\title{
Informal Labor in the Sharing Economy: Everyone Can Be a Record Producer
}

\author{
David Arditi
}

The availability of Digital Audio Workstations (DAWs) - digital software that allows musicians and producers to record music on a computer - changes the social relations of production in the studio. Much as digital music stores helped to close bricks-and-mortar music stores (Arditi 2014c), cheap DAWs have made large record studios increasingly obsolete. The informality of digital media does not end with distribution and consumption, but extends to labor in the production of digital culture. With digital technology, everyone can be a record producer, but even fewer people can make a living from record production.

Sharing is fundamental to rhetorical discussions of the Internet. Jonas Andersson Schwarz claims "'Sharing" has become one of the most telling pastimes of our digital, networked age" (Andersson Schwarz 2013:1). There are four uses of the term "sharing" as relates to the Internet. First, we can talk about file sharing and the gift economy. Matthew David claims that file sharing has "the potential to circulate [informational] goods freely through the Internet," which he contends could lead to the end of scarcity of informational goods (2010:2). Proponents of file sharing claim "information wants to be free." Of course, the Culture Industry sees file sharing as a threat to their monopoly on cultural commodities. Second, there is the idea of sharing one's ideas, thoughts, pictures, and daily routines with others through social media. Ben Agger labels this narcissistic tendency "oversharing" as we begin to put our every detail on the Internet for everyone to see (2011). What was once private has become public as we share likes, dislikes, secrets, and obsessions to everyone on the Internet. Third, sharing is a code word for Internet corporations with regard to what they do with our data. In this case "sharing" is a substitute for "selling" that intentionally obscures our understanding of sharing in the first two senses (Fuchs 2013).

Fourth, a sharing economy implies an informal economy where people sell the use of things they own. As Juliet Schor defines "the new sharing economy as economic activity that is Peer-to-Peer, or person-to-person, facilitated by digital platforms" (2015). Platforms place people in contact with each other to "share" goods and time. Advocates of the sharing economy claim that these platforms make under-utilized goods productive. In effect, "sharing" is selling the usage rights to an owned commodity. However, sharing could be viewed as unending labor-a type of labor power dependent on the constant work of individuals under precarious circumstances. These workers "have no protections - not even minimum wage guarantees — when payment is by the job, rather than by time" (Schor 2015). From Uber and Airbnb to Favor and Rent Like a Champion, mobile devices have become tools for the informalization of labor - a process where companies describe themselves as web-platforms instead of cab companies, delivery services or hotels. In effect, the workers own their means of production, but the tech companies use their brand power to connect workers to customers. It is in the fourth sense that I am exploring the way record producers become "sharing" entrepreneurs whereby they sell access to their studios.

The social relations of production in recording studios changes as musicians and labels stop using large recording studios. Record production has been scattered through a number of smaller craft studios, which fundamentally changes the work environment for people working in studios. The prospect of full time employment in large studios has always been a challenge, and studio workers are known to labor precariously to earn a living; however, DAWs have rapidly increased this precariousness over the last several decades. Many of these workers live job-to-job or toil in part-time positions in other industries hoping to catch a break with their music production career. This new form 
of production gives corporations a means to increase capital by cutting production budgets.

The digital transition of recording studios is not the logical outcome of the progress of technology, but rather a product of the logic of capitalism. A raw technological determinism assumes that technology is devoid of ideology and that the creation of new technology can only mark progress that advances society and humanity. However, it is important to remember that technological development is embedded within a particular set of social relations. In Noise: The Political Economy of Music (1985), Jacques Attali proposes that the political economy of music predicts or foreshadows shifts in the economic system. For instance, workers in the sharing economy have been described a "turn toward precarious employment and the privatization of risk . . more accurately understood as the ' 1099 economy,' since their workers are not employees receiving IRS W-2 forms, but 1099-MISC forms. That is they are temporary contractors" (Walker 2015). Musicians have worked as temporary contractors filing 1099 tax forms for decades whether they are gigging musicians, session musicians, or signed to a record contract. The sharing economy models itself on the informal labor structure under which musicians have been oppressed. With regard to record production, there is a remarkable similarity between the displacement of studio production from large label studios to small project (typically home) studios and the overall shift from large corporate owned services to the sharing economy.

While the informalization of labor in the production of music is not necessarily linked to an online platform that operates under the guise of sharing, there are distinct similarities to the precarity of labor that occurs with digitization. This essay outlines the changes to the recording studio, then critiques these changes in terms of their influence on the conditions of labor. I conclude by discussing the website platform, SoundBetter-a site designed to connect musicians and music production workers to record music. I use a Cultural Studies methodology that interrogates a cultural object (music studios) with the goal of illuminating the situatedness of that object within a broader social discourse. To do this, I employ the method of immanent critique as "a means of detecting the societal contradictions which offer the most determinate possibilities for emancipatory social change” (Antonio 1981:330). What follows is a theorization of the effects of digital music production on the social relations of production in new studio spaces.

\section{| Digitizing and Decentering the Studio}

As large studios developed in a handful of major cities, other studios clustered nearby to exploit the available labor. Allen Scott contends that this "clustering together of many different types of firms and specialized workers in one place provides all participants in the industry with a form of social insurance in the sense that clustering will almost always guarantee a relatively high probability of finding just the right kind of input within easy access at just the right time" (Scott 2000:121). In other words, record labels and musicians cluster in New York, Los Angeles, and Nashville because there are already musicians in those locations.[2] Clustering creates easy access to a pool of qualified musicians, producers, engineers, Artist \& Repertoire (A\&R) staff, and composers. With all of these different types of labor near each other, capitalism has an efficient system of production because little time and resources are lost seeking out the right types of labor to exploit; clustering creates a reserve army of labor. As a result, record labels built studios in these key cities to exploit the cultural labor that existed in these locations. Large record label-owned or established studios allowed capital to expropriate labor at a high profit; however, DAWs are upending the institutional need for these large studios and replacing them with smaller decentralized studios.

Large studios operate under a Fordist economic model. Their goal is to produce a large quantity of music with nominal costs. The most effective strategy to produce music was to develop an economy of scale. Berry Gordy perfected this model in the Detroit-based Motown Studios, 1959-1972, where composers/authors, musicians, engineers, producers, directors worked under the same roof (Smith 2001). Gordy's model operated through a logic where the parts were interchangeable (Horkheimer and Adorno 1972); a song written by Holland-Dozier-Holland (a Motown songwriting team) could be recorded by Motown session musicians, vocals could be recorded by both Stevie Wonder and Marvin Gaye, then ultimately Motown management could decide which recording artist would have the song on their album. This was possible because of the location of surplus army of musical labor in one place.

This model was used across the recording industry. Again, this is based on an economy of scale. If we just consider janitorial services, one large studio that has the capacity to record multiple sessions at the same time could employ one janitor to clean the floors and bathrooms of a large studio, but if the studio were half the size and split 
into two locations, two janitors would be needed to keep the studio clean. I mention janitors because this is how deeply embedded labor is in these studios. On the production level, a team of sound engineers in a large studio allows an engineer to set-up a session in one room while recording is taking place in a different room. Their labor is always necessary around the studio on a rotating basis to keep projects moving through the studio. While the clustering of labels in specific cities allowed for the grouping together of various types of labor across the recording industry (Scott 2000), these studios allowed for fewer workers on a larger scale.

Since analog recording equipment was so expensive, recording studios required significant capital to open; this meant that record labels were ideal owners of studios. Recording studios have been the main element of the means of production in the recording industry because instruments and other performance gear is relatively cheap. Therefore, record labels owned recording studios as a means to employ various types of labor to produce music. The reason why musicians recorded in these large studios was simple: musicians did not have the capital to own the means of production to record music. If musicians wanted to record and sell music, they had to pay for time in a studio. Ownership of the means of production is so important to capitalism because it is what allows capital to exploit labor. Since labor cannot afford to produce records on their own, they need to work for capital. However, all of this changes with DAWs because of the diminution of the cost of recording equipment. This decline in the cost of recording equipment has led to the closing of recording studios.

For example, the closure of Room With A View studios illustrates the expense to run a high-end recording studio. Billboard closely followed the development of Room With A View studios going as far as to consider this small one-room facility "one of the top mixing facilities in the world" used by recording artists such as Dave Matthews Band, Ozzy Osbourne, Paula Cole and The Verve Pipe (Verna 1997). The excitement around the studio, which opened in 1994, stemmed from the studio's purchase of a Solid State Logic (SSL) 9000 J series console, a recording console that cost "hundreds of thousands of dollars" (Verna 1997). Slightly over a year later in 1998, Paul Verna reported a story about the closure of Room With A View. In this later story, former studio owner Alessandro Cecconi stated the following:

"When we got our 9000, there were three in town," he says. "Now there are eight or nine, and SSL is dropping their prices, so the studios are dropping their rates. You can get an 80 -channel board for $\$ 400,000$. As a studio owner, you never win. You put in a 9000 and you sell your room for $\$ 2,000$ a day. Then the next guy puts one in and charges $\$ 1,800$ a day. Then the next guy charges $\$ 1,600 "$ (Verna 1998a).

This illustrates the high cost of high-end recording studios. Cecconi attempted to create a high-end recording studio on a small-scale to compete with the large multi-room studios run by the major record labels. While Cecconi blames the cost of SSL for his studio's failure, a point that SSL vehemently denies (Verna 1998b), this episode exemplifies the barrier for small studios to purchase the means of production to compete on equal ground with the majors. For a major record label or an established multi-room studio, a $\$ 400,000$ piece of equipment is an investment in a business that can be made by reinvesting capital, whereas, Room With A View undoubtedly received a loan to purchase the equipment that would ultimately have to be paid off with more expensive studio time. This initial difference in capital reflects the capacity for different types of studios to charge different daily rates; large concentrated firms will always be able to stifle the competition similar to the effects of Walmart on small businesses in the retail industry. And yet, it is an irony that Room With A View made an attempt to compete with large studios by purchasing an expensive recording console at a time when expensive recording equipment was quickly becoming unnecessary.

A transformation to this model of large recording studios began decades ago because studio equipment has become less expensive, smaller, and more portable. As the smaller and cheaper equipment has improved in quality, "the distinction between what can be considered a 'professional' or 'commercial' project studio and simply a 'personal' or 'home' studio has become increasingly difficult to make" (Théberge 2012:83). Since high quality recording technology is available in the home that is indistinguishable from that available in expensive studios, there has been widespread adaptation of these technologies by musicians and producers. A report by Billboard about the closing of Hit Factory in New York City and Cello Studios in Los Angeles within five days in 2005 points to the fact that music can be "completed in small, inexpensive DAW-based suites, some of them personal or home studios" (Walsh 2005). The low cost of new recording technology has lowered the cost of the means of production displacing the importance of large studios in the recording process. Even Sony Studio, one of the last unionized studios in NYC was valued "more as real estate than any amount of financial gain, organization efficiency or corporate prestige" (Théberge 2012:78). In other words, even the organizational efficiency and corporate inertia of large studios was 
no match for the increased efficiency of outsourcing studio work to independent producers. Susan Christopherson highlights a similar process in the film and television industries where "new technologies have also affected content production, making it less expensive and adapted to the demand for inexpensive programming. In particular, lightweight video, lighting and audio equipment have made it possible to reduce the number of people necessary for a 'shoot"' (Christopherson 2008:79). Because cheaper production processes are available, film and television budgets have decreased, thereby forcing producers to produce content on smaller budgets using cheaper technologies; this is precisely the process taking place in the recording industry.

Large studios have been closing around the country. Mergers have been the source of some closures, such as the A\&M Recording Studios complex, which closed as a result of Universal Music Group's purchasing of Polygram records in 1999 (Verna 1999). In New York City, Hit Factory, famous for recording artists from Paul Simon to Michael Jackson, closed its doors in 2005 and is now luxury condos (Rose 2009). As Billboard contends, "inexpensive, highquality digital recording equipment has increasingly enabled musicians to take production into their own hands," a trend that the recording industry's trade journal claims to find "troubling" in places like Austin, Texas (Walsh 2003). I highlight the word troubling because it implies a degree of conscience on the part of Billboard; however, the overall thrust of the content in Billboard emphasizes the profitability of major record labels. To that end, the closing of studios in Austin, Texas signals the reduced costs for major record labels to produce and sell albums. In fact, later in the same article (Walsh 2003), Billboard blames the closing of Austin's studios on the declining major label recording budgets; however, the article does not connect the availability of cheap recording equipment with the declining budgets.

What causes the decline of major record label recording budgets? The dominant narrative perpetuates the idea that declining budgets are a direct result of declining music sales. As an example, an article in the Christian Science Monitor relays the narrative that "following the downturn in music sales this decade, many studios are struggling or simply have closed their doors" (Guarino 2009). This articulation implies that studios are closing because of declining music sales. However, as I have demonstrated elsewhere (Arditi 2014b, 2014c), this argument is specious because the major record labels define this narrative. A critical analysis of the status of recording budgets points in a different direction: the decline of the cost of the means of production (in this instance, recording equipment and space) led to smaller budgets. Smaller budgets are a result of the logic of capitalism. Why would a label budget for a $\$ 2,000 /$ day studio when it can budget for a studio that charges $\$ 500 /$ day? Major record labels will not spend unnecessary money on the recording process. Because recording can be done on a small scale from small/boutique/ producer-owned/home studios, there is no longer a need for record labels' budgets to support the overhead cost of running a large recording studio. The new low cost of the means of record production dislodged production by forcing the closure of large studios and changing the space of record production to decentralized small studios.

There are parallels to the growing sharing economy in the ability for workers to own, at least, part of the means of production. Uber and Lyft are known as "rideshare" services because they allow vehicle owners to act as taxi drivers. People who own cars can drive passengers for a fee on their "free" time. This is significantly different from driving for a taxi cab company or limousine service where the company owns the vehicle and the drivers are employees who need the company to earn a wage. With ridesharing, Uber and Lyft do not own the vehicles (at least for most of their services), but rather count on crowdsourcing drivers and their cars throughout selected cities. Ridesharing services define themselves as web platforms because their applications connect passengers to drivers. NeighborGoods is a website that allows individuals to rent their tools. CouchSurfing and Airbnb connect people willing to rent their homes to travelers.

In each case, the company earns revenue from workers who use their own means of production, but would lack the cumulative network of people using these services to generate a wage from driving or renting their own equipment. Small studios work in a similar way where studio "owners" (people with a laptop and several microphones) can record their own music and record the music of others, but their studios lack the reputation to gain the recordings any recognition.

Owning a personal home studio has become a significant part of a musician's identity. In an ethnography of the underground hip-hop music scene entitled "Get on the Mic: Recording Studios as Symbolic Spaces in Rap Music" (2014), Geoff Harkness investigates the role of studio space in rap music. In Harkness' illustration of the symbolic spaces in which emcees record and produce their music, I see two levels of craft production. First, Harkness describes the studio space of National Sound, a "professional studio with enough computer gear and digital paraphernalia to fill a small airplane hangar" (Harkness 2014:82). Second, Harkness identifies the myriad varieties of home studio spaces. These spaces remove the centrality of capital in the recording process because they 
allow for the dispersal of recording sites. However, these new spaces more thoroughly point to the informalization of labor that is a quintessential part of the contemporary recording industry and sharing economy more generally.

\section{Informalizing Labor}

Before the proliferation of DAWs and cheap recording equipment, musicians were the primary source of precarious casual labor in the recording industry. Many musicians have an ideology that to succeed in their craft, they need to sign a record contract, and as part of that ideology, they earn a living by not committing themselves to a stable career. Rather, musicians dedicate their lives to one day "making it" in the music business by playing gigs at night and working part-time jobs or teaching music lessons during the day. In doing so, these musicians accept whatever type of work can permit them the flexibility to set their own schedule. Since they see their primary source of work (i.e. being a musician) as flexible and casual, they are willing to accept other forms of flexible and casual employment to supplement their income (Arditi 2014a). This has been the labor model for musicians for the better part of a century. Attali's proclamation that the political economy of music foreshadows the broader political economic system is relevant here because the global economic system shifted to embrace the contingent nature of employment for musicians for all types of labor. "Capital-owners have won lavish returns from casualization - subcontracting, outsourcing and other modes of flexploitation - and increasingly expect the same in higher-skill sectors of the economy. As a result, we have seen the steady march of contingency into the lower and middle levels of the professional and high-wage service industries" (Ross 2008:34). As Andrew Ross suggests, capital is instituting precarious labor at all levels and in all types of labor. This has been implemented through the language of creativity and creative workers under the argument that for workers to be the most productive and happiest, they must be given the space to have a flexible work environment. The non-musician labor in the recording industry is increasingly emulating the labor conditions of musicians. While some workers within the Culture Industry have made considerable money from flexible outsourced label, far more make less money.

In large multi-room studios, there are a number of labor positions necessary for the everyday functioning of the studio. As discussed above, this labor includes everything from the janitorial staff to sound engineers. Large studios employ these workers on a full-time basis to ensure a smooth operating studio. Therefore, these studios must pay employees for working full-time, which includes complying with state-mandated benefits for full-time employees. This is the "organizational efficiency" (Théberge 2012) discussed above; because record labels owned large studios, they already had labor within these studios. There is no need to locate workers in large studios, and negotiate their wages because they were part of the studio. Small studios work under a mode of production where the cost of the means of production is shifted to labor itself.

The political economy of this scenario is interesting because of the way the new model places the economic burden on subcontracted labor - an expansion of the so-called "1099 economy" discussed above. As a hypothetical example, whereas an established studio may charge \$1500-2,000/day for the use of a studio, a small professional project studio may charge $\$ 50 /$ hour (or $\$ 400$ for an eight-hour day). The availability of cheap digital recording equipment is not enough to explain this decrease in price; it can only be described in terms of a parallel reduction in labor costs. As Susan Christopherson characterizes this process, "large media firms are paring down their production workforces to an essential core and using temporary workers and self-employed workers on an as-needed basis" (Christopherson 2008:83). In other words, record labels reduce the cost to produce albums by relying on contingent labor that not only produces music at a lower cost, but also does this by employing fewer workers. Small project studios are operated generally by the owner who acts as owner/producer/engineer/janitor as is the case with Abe at National Sound (Harkness 2014). Even in instances where the producer has a big name, these relations of production require the producer to determine his/her studio's labor configuration to meet the demands of a budget. In other words, it is the producer's decision who to hire to help run the studio. Unfortunately, this has led to both a reduction in the number of employees necessary in a production studio and the amount that producers are willing to or required by law to pay employees. Therefore, digital studios have led to the increasingly precariousness of employment for workers in the recording industry.

The concept of "precariousness" used by many Autonomist Marxists and critical media theorists is relevant to this labor position. As labor flexibility increases, it erodes at Marx's concept of the reserve army of labor. Michael Hardt and Antonio Negri posit that "What is called the flexibility of the labor market means that no job is secure" 
(2004:131). Without job security, even the employed are unsure of their future employment and many workers remain underemployed as they string together odd jobs to try to pay bills. "Precariousness (in relation to work) refers to all forms of insecure, contingent, flexible work - from illegalized, casualized and temporary, to homeworking, piecework and freelancing" (Gill and Pratt 2008:3). Whereas many economists promote creative labor as a model for all labor, Gill and Pratt argue precisely the flexibility of so-called "creative workers" places them in an insecure position. For instance, the two types of new project studios, described by Harkness (2014), allow for endless tinkering on the part of musicians, and in the professional project studios, it overworks the staff of the studio for little pay. The musician's home tinkering is a form of homeworking that advances itself in perpetuity - a musician will spend all of his/her free time working on a track to "perfect" it, but there is no compensation for time-spent working. Meanwhile, producers who open their own studios must always work to find musicians to record sessions because their survival is contingent on a demand for studio space. If their studio business is struggling to remain open, the producer-owner must be willing to record whenever musicians would like to record. Whereas labor in a Fordist industrial model is guaranteed a wage as long as they remain employed, precarious employment is dependent on the whims of demand and the insecurity of the next project.

Precarity is demonstrated throughout the record industry. In The Death \& Life of the Music Industry in the Digital Age (2013), Jim Rogers calls the celebrity status of particular producers the "cult" of the record producer. Rogers suggests that "record producers now exist as individual brands in their own right. Beyond serving to shape or define the sound of the record, many producers, courtesy of the elevated status they have come to enjoy, are widely perceived as fundamental to enhancing the public profile of the artists they produce" (Rogers 2013:193).

Producers become larger than the artists themselves. As a result, picking the right producer(s) for an album contributes to the overall success of the album. For instance, Adele's album 25 , which was always destined to go multi-platinum benefited directly from the cult of the record producer. In Rolling Stone's review of 25 , the reviewer explains that "pop's biggest names, from Max Martin to Bruno Mars, join familiar faces like Paul Epworth and Ryan Tedder in 25's dream team of producers and co-writers" (Dolan 2015:61). These are producers/songwriters with the biggest hits at the time; their names and reputations almost guarantee a hit album. Furthermore, Rogers insists this gives lesser-known artists access to larger audiences. It is important to note that this has little to do with production quality, and is more closely related to the producer's brand.

Moreover, "big-name producers are largely only accessible through one of the major labels," which Rogers argues "helps to maintain and bolster an oligopolistic industrial structure" (Rogers 2013:194). Since big-name producers are available only to major label artists, the cult of the producer leads to even greater distinctions between music produced by majors and independents. The class divide between majors and independents grows deeper because independent artists can only use non-major-affiliated producers who do not have the brand-power to expose their music to a larger audience.

To help with the recording process, owner-producers seek even more contingent/flexible/casual labor. Many project studios turn to interns to fill the labor gaps in their studios. Whereas the traditional studio model used apprentices to do much of the less skilled labor around the studio and paid sound engineers to facilitate the recording process, today's project studios focus on interns. In some instances, studios open "their doors to interns for a fee, thus generating income during periods when the studio would otherwise be unused" (Théberge 2012:88). In other words, the precariousness of project studio employment encourages owner-producers to use further types of casualized labor and go as far as charging them for their exploitation. Alexandre Frenette (2013) reveals the precariousness of interns working for the major record labels. In a way, the interns who Frenette describes at the major record labels represent a privileged position compared to those working at project studios because the major labels operate within the work standards of labor laws-however low those standards are for interns. Since project studios may operate without licenses, there may not be documentation that an individual interns at a project studio; this increases the precariousness of the intern's labor.

By contracting studio work to small independent project studios, major record labels create disturbing labor practices that exploit the disempowered character of studio owner-producers. People that want to work in recording studios do so only in the most precarious of labor relations. Ultimately, the most practical way to make money working in a recording studio is for aspirant producers to build their own studios because their work is too contingent otherwise. However, opening one's own studio is also a quick route to bankruptcy because the lack of contracts and competition among producers makes owning a studio unstable. Major record labels continue to decrease recording budgets for their recording artists because they know how the system of outsourcing works to minimize costs. Recording artists seek out cheaper studios to make their recording budgets go further. As a result, there is a race 
to the bottom among project studio owners who are desperate to slash their rates to compete against the alwaysincreasing number of project studios

\section{Conclusion}

Already, a web platform exists to find "freelancers" to record your album. SoundBetter is a website with lofty goals to "democratize the music production world, to help pros get work remotely, to increase transparency via verified reviews and help the huge market of self producing musicians securely connect with the right partners from anywhere in the world" (https://soundbetter.com/about, February 1, 2016). By promising a "democratic" structure, SoundBetter elicits the connotation that all are created equal. There is a free "Basic" plan that allows producers, beatmakers, mixers, musicians, sound engineers, etc. to create a profile and use the platform. However, there is a tiered pricing plan for $\$ 39 /$ month or $\$ 395 /$ year to have greater access (which includes access to the job board-an important feature for people who want to make a living through the site). So in practice, SoundBetter parallels American democracy where people with money have greater access than the poor masses. At the same time, SoundBetter generates revenue from users regardless of whether these users actually receive gigs. By placing people in contact with potential producers, beatmakers and sound engineers, SoundBetter extracts profit from the dreams of aspiring record producers without giving them much other than a central place to be found.

Record producers in small studios are independent contractors who rely on landing gigs to earn an income. This essay opens lines of inquiry for future work around three ideologies that induce producers to work in the informal economy. First, producers succumb to the ideology of creative autonomy. Second, many producers endlessly tinker with their music with the hope to one day "make it" and be released from their everyday struggle. Third, producers believe that the path to celebrity requires dedicating all of their time to their craft.

When everyone can be a cab driver, hotelier or record producer, no one can make a living from driving people around, renting out a room or recording music. For example, by driving for Uber in one's "free" time, it reduces the number of riders available to people driving full time. Not only do people fail to make a living from these activities, there is no solidarity between workers and no chance of unionization. In the music industry, there are no credible data on the number of workers - the U.S. Bureau of Labor statistics has no way to track the number of people who work as producers. While musicians have always had this precarity, the rest of the economy is following their lead to become an economy of 1099 workers. Virtually no one can make a living producing music, but that does not stop the dreamers from toiling to hit it big.

\section{Endnotes}

1. This article is derived, in part, from an essay published in The production and consumption of music in the digital age on April 26, 2016.

2. Of course, there are varying reasons why these cities became sites for the recording industry. For example, Los Angeles developed as musicians from across the United States migrated to be close to film recording (Zinn, Kelley, and Frank 2002). 


\section{References}

Agger, Ben. 2011. Oversharing: Presentations of Self in the Internet Age. New York, NY: Routledge.

Andersson Schwarz, Jonas. 2013. Online File Sharing: Innovations in Media Consumption. 1st edition. New York: Routledge.

Antonio, Robert J. 1981. "Immanent Critique as the Core of Critical Theory: Its Origins and Developments in Hegel, Marx and Contemporary Thought." The British Journal of Sociology $32(3): 330-45$.

Arditi, David. 2014a. "Digital Downsizing: The Effects of Digital Music Production on Labor." Journal of Popular Music Studies 26(4):503-20.

Arditi, David. 2014b. iTake-Over: The Recording Industry in the Digital Era. Lanham, Maryland: Rowman \& Littlefield Publishers.

Arditi, David. 2014c. "iTunes: Breaking Barriers and Building Walls." Popular Music and Society 37(4):408-24.

Attali, Jacques. 1985. Noise: The Political Economy of Music. Minneapolis: University of Minnesota Press.

Christopherson, Susan. 2008. "Beyond the Self-Expressive Creative Worker: An Industry Perspective on Entertainment Media." Theory, Culture \& Society 25(7-8):73-95.

David, Matthew. 2010. Peer to Peer and the Music Industry: The Criminalization of Sharing. Los Angeles: Sage Publications Ltd.

Dolan, Jon. 2015. “Welcome to Adele's Brave New World.” Rolling Stone, December 17, 61-62.

Frenette, Alexandre. 2013. "Making the Intern Economy: Role and Career Challenges of the Music Industry Intern." Work and Occupations 40(4):364-97.

Fuchs, Christian. 2013. Social Media: A Critical Introduction. Thousand Oaks, CA: SAGE Publications Ltd.

Gill, Rosalind and Andy Pratt. 2008. "Precarity and Cultural Work: In the Social Factory? Immaterial Labour, Precariousness and Cultural Work." Theory, Culture \& Society 25(7-8):1-30.

Guarino, Mark. 2009. "Could Home Recording Doom Professional Music Studios?” Christian Science Monitor, December 17. Retrieved May 20, 2014 (http://www.csmonitor.com/Innovation/2009/1217/ Could-home-recording-doom-professional-music-studios).

Hardt, Michael and Antonio Negri. 2004. Multitude: War and Democracy in the Age of Empire. New York: The Penguin Press.

Harkness, Geoff. 2014. "Get on the Mic: Recording Studios as Symbolic Spaces in Rap Music." Journal of Popular Music Studies 26(1):82-100.
Horkheimer, Max and Theodor W. Adorno. 1972. "The Culture Industry: Enlightenment as Mass Deception.” P. xvii, 258 p. in Dialectic of Enlightenment. [New York]: Herder and Herder.

Rogers, Jim. 2013. The Death and Life of the Music Industry in the Digital Age. New York: Bloomsbury Academic.

Rose, Joel. 2009. "Recording Studios Face Uncertain Future.” All Things Considered. Retrieved May 20, 2014 (http://www.npr.org/2009/12/10/121304883/ recording-studios-face-uncertain-future).

Ross, Andrew. 2008. "The New Geography of Work Power to the Precarious?” Theory, Culture \& Society 25(7-8):31-49.

Schor, Juliet B. 2015. "Getting Sharing Right." Contexts, 14-15.

Scott, Allen John. 2000. The Cultural Economy of Cities: Essays on the Geography of Image-Producing Industries. London ; Thousand Oaks, Calif.: SAGE Publications.

Smith, Suzanne E. 2001. Dancing in the Street: Motown and the Cultural Politics of Detroit. Cambridge, Mass.: Harvard University Press.

Théberge, Paul. 2012. "The End of the World as We Know It: The Changing Role of the Studio in the Age of the Internet." Pp. 77-90 in The Art of Record Production: An Introductory Reader for a New Academic Field, edited by S. Frith and S. Zagorski-Thomas. Ashgate Publishing, Ltd.

Verna, Paul. 1997. "In N.Y., a Room With A View That Draws Top Mixers." Billboard, June 21, 46.

Verna, Paul. 1998a. "Room With A View's Closing Illustrates Harsh Realities.” Billboard, October 24, 52.

Verna, Paul. 1998b. "SSL And Others Sound Off On Room With A View's Closure.” Billboard, October 31, 40.

Verna, Paul. 1999. "Universal Closes A\&M Studios Complex." Billboard, October 9, 3 .

Walker, Edward T. 2015. "Beyond the Rhetoric of the 'Sharing Economy."” Contexts, 15-17.

Walsh, Christopher. 2003. "DIY Recording Spells Tough Time for Austin's Studios." Billboard, March 15, 1, 74.

Walsh, Christopher. 2005. "Studio Closings Stun Audio World." Billboard, February 19, 6-72.

Zinn, Howard, Robin D. G. Kelley, and Dana Frank. 2002. Three Strikes: Miners, Musicians, Salesgirls, and the Fighting Spirit of Labor's Last Century. Boston: Beacon Press.). 